\title{
Erosive Effect of Different Soft Drinks on Enamel Surface in vitro: Application of Stylus Profilometry
}

\author{
Radomir Barac ${ }^{a}$ Jovanka Gasic ${ }^{a}$ Natasa Trutic ${ }^{b}$ Slavica Sunaric ${ }^{b}$ \\ Jelena Popovic ${ }^{a}$ Petar Djekic ${ }^{c}$ Goran Radenkovic ${ }^{c}$ Aleksandar Mitic $^{a}$ \\ ${ }^{a}$ Department of Restorative Dentistry and Endodontics, Clinic of Dentistry, Faculty of Medicine, ${ }^{b}$ Department \\ of Pharmacy, Faculty of Medicine, and 'Department of Production Engineering, Faculty of Mechanical Sciences, \\ University of Nis, Nis, Serbia
}

\section{Key Words}

Soft drinks · pH · Titratable acidity · Dental enamel · Surface roughness $\cdot$ Stylus profilometry

\begin{abstract}
Objective: To assess the erosive potential of various soft drinks by measuring initial $\mathrm{pH}$ and titratable acidity (TA) and to evaluate enamel surface roughness using different exposure times. Materials and Methods: The initial $\mathrm{pH}$ of the soft drinks (group 1: Coca-Cola; group 2: orange juice; group 3: Cedevita; group 4: Guarana, and group 5: strawberry yoghurt) was measured using a $\mathrm{pH}$ meter, and TA was measured by titration with $\mathrm{NaOH}$. Enamel samples $(\mathrm{n}=96)$, cut from unerupted human third molars, were randomly assigned to 6 groups: experimental (groups 1-5) and control (filtered saliva). The samples were exposed to $50 \mathrm{ml}$ of soft drinks for 15, 30 and 60 min, 3 times daily, during 10 days. Between immersions, the samples were kept in filtered saliva. Enamel surface roughness was measured by diamond stylus profilometer using the following roughness parameters: $R_{a}, R_{q}, R_{z}$ and $R_{y}$. Data were analyzed by one-way ANOVA, Tukey's post hoc and Student-Newman-Keuls post hoc tests. Results: The $\mathrm{pH}$ values of the soft drinks ranged from 2.52 (Guarana) to 4.21 (strawberry yoghurt). Orange juice
\end{abstract}

had the highest $\mathrm{TA}$, requiring $5.70 \mathrm{ml}$ of $\mathrm{NaOH}$ to reach $\mathrm{pH}$ 7.0, whereas Coca-Cola required only $1.87 \mathrm{ml}$. Roughness parameters indicated that Coca-Cola had the strongest erosion potential during the $15 \mathrm{~min}$ of exposure, while Coca-Cola and orange juice were similar during 30 - and $60-\mathrm{min}$ exposures. There were no significant differences related to all exposure times between Guarana and Cedevita. Strawberry yoghurt did not erode the enamel surface regardless of the exposure time. Conclusion: All of the tested soft drinks except yoghurt were erosive. Erosion of the enamel surfaces exposed to Coca-Cola, orange juice, Cedevita, and Guarana was directly proportional to the exposure time.

๑) 2015 S. Karger AG, Basel

\section{Introduction}

Dental erosion is defined as the irreversible loss of dental hard tissue by prolonged and frequent acid action (extrinsic and intrinsic) without bacterial involvement [1]. Numerous studies have reported that acids present in food and soft drinks (fruit juices, sports and energy drinks) represent a major etiological factor responsible for the erosive lesions of dental enamel [2-4]. 
Table 1. The soft drinks and various substances in their composition as marked on the original packaging

\begin{tabular}{ll}
\hline Tested agents (brand name/producer) & Composition \\
\hline $\begin{array}{l}\text { Coca-Cola } \\
\text { (HBC - Serbia A.D. Zemun) }\end{array}$ & $\begin{array}{l}\text { Water, sugar, carbon dioxide, color (caramel, E150d), } \\
\text { phosphoric acid, natural flavorings including caffeine }\end{array}$ \\
\hline $\begin{array}{l}\text { Orange juice } \\
\text { ('NECTAR' D.O.O., Backa Palanka, Serbia) }\end{array}$ & Water, concentrated orange juice, citric acid \\
\hline $\begin{array}{l}\text { Cedevita } \\
\text { ('CEDEVITA' d.o.o., Zagreb, Croatia) }\end{array}$ & $\begin{array}{l}\text { Sugar, citric acid, acidity regulator: hydrogen carbonate, natural } \\
\text { lemon flavor, color (betanin and } \beta \text {-carotene), thickener (E414), } \\
\text { vitamins }\end{array}$ \\
\hline $\begin{array}{l}\text { Guarana } \\
\text { ('KNJAZ MILOS' a.d., Aranđelovac, Serbia) }\end{array}$ & $\begin{array}{l}\text { Water, sugar, carbon dioxide, citric acid, taurine, guarana flavor, } \\
\text { caffeine, vitamin blend, preservative sodium benzoate, color } \\
\text { (E150d) }\end{array}$ \\
\hline $\begin{array}{l}\text { Fruit yoghurt } \\
\text { (AD IMLEK Dairy, Belgrade, Serbia) }\end{array}$ & $\begin{array}{l}\text { Pasteurized milk, processed strawberries (sugar, strawberries, } \\
\text { modified starch, thickeners: pectin and caruba gum, flavor, } \\
\text { Cochineal Red A color), yoghurt culture }\end{array}$ \\
\hline
\end{tabular}

Even though soft drinks are mainly composed of filtered water, artificial additives and refined sugar, thus offering limited nutritional benefit, they still boost energy. Sports drinks, designed to replenish fluids lost during activity, typically contain water, electrolytes and sugar. Energy drinks are basically soft drinks containing vitamins and other chemicals that boost energy for a very short span [4]. Also, differences in lifestyle, behavior and habits during the consumption of acidic food and drinks are often considered as potential factors of erosion. Unusual eating, drinking and swallowing habits, for example holding an acid beverage in the mouth before swallowing, swishing around the mouth or sucking juice through the teeth, increases the contact time of an acidic substance with the teeth and thus increases the risk of erosion [5]. According to Jager et al. [6], exposure times between 3 and $30 \mathrm{~min}$ result in very different estimates of erosive potential.

Important parameters for the soft drink erosive potential are $\mathrm{pH}$ value and titratable acidity (TA) $[1,2,4,7]$. The $\mathrm{pH}$ value corresponds to the equilibrium measure of the hydrogen ion concentration, but it does not indicate the overall acidic content of the drink or food, whereas TA gives a measure of all free hydrogen ions available to cause erosion $[1,2]$. Several previous studies utilized $\mathrm{pH}$ and TA measurements to characterize test soft drinks [1, 2].

Apart from chemical aspects of erosion, physical characteristics of enamel surface were evaluated to indicate the loss of tissue due to exposure to soft drinks with low $\mathrm{pH}$ values. These characteristics can be evaluated by mea- surement of roughness parameters along a line by contact stylus surface profilometry. Therefore, the aims of the present in vitro study were 2 -fold: (1) to assess the erosive potential of different soft drinks (Coca-Cola, orange juice, Cedevita, Guarana, and strawberry yoghurt) by measuring the initial $\mathrm{pH}$ and $\mathrm{TA}$ and (2) to evaluate enamel surface roughness $\left(R_{a}, R_{q}, R_{z}\right.$, and $\left.R_{y}\right)$ after erosive challenge in soft drinks with different exposure times using diamond stylus profilometry.

\section{Materials and Methods}

A total of 5 commercially available soft drinks were tested (2 carbonated drinks: Coca-Cola and Guarana; 1 sports vitamin drink: Cedevita; 1 fruit juice: orange juice, and 1 strawberry yoghurt; table 1). Four commercial packages for each soft drink were taken from the local shops. In order to evaluate TA, triplicate measurements of $\mathrm{pH}$ and 3 repeated titrations were carried out for each sample.

\section{pH Measurement}

The initial $\mathrm{pH}$ of each soft drink was measured by using a Metrohm $827 \mathrm{pH}$ lab pH meter (Metrohm AG, Switzerland). The electrode was calibrated at the beginning of each session using standard buffers of $\mathrm{pH} 5.5$ and 7.0. After that, $50 \mathrm{ml}$ of freshly opened soft drink at room temperature was placed in a beaker and stirred using a nonheating magnetic stirrer until a stable reading was obtained. A total of 3 readings were taken of each sample drink to give a mean measurement of the $\mathrm{pH}$ of that drink.

\section{TA Assessment}

TA was estimated by titration with a standard $\mathrm{NaOH}$ solution using the potentiometric titration method. For each soft drink aliquots of $0.25 \mathrm{ml}$ of $1.0727 \mathrm{M} \mathrm{NaOH}$ were added in $50 \mathrm{ml}$ of drink 
until $\mathrm{pH}$ reached 5.5 and 7.0 [2]. After each addition of $\mathrm{NaOH}$ the specimens were again stirred using a nonheating magnetic stirrer until a stable $\mathrm{pH}$ reading was obtained. Titrations were repeated 3 times for each drink and an average value was calculated.

Statistical analysis of the initial $\mathrm{pH}$ and TA of the soft drinks was performed using one-way ANOVA and Tukey's post hoc tests in order to determine differences in the mean values among the groups. There was a statistically significant difference if $\mathrm{p}<$ 0.05 .

\section{Preparation of Samples for Profilometric Analysis}

This study was approved by the institution's ethics committee. A total of 24 nonerupted human third molars which had been surgically extracted for medical reasons from patients (aged 18-25 years) were taken. The teeth were disinfected in $1 \%$ thymol solution until preparation. For cleaning, the teeth were stored in $1 \%$ sodium hypochlorite for $24 \mathrm{~h}$. Organic debris was removed by carefully using a dentist's set of instruments [8].

Sample preparation for profilometric analysis was performed according to previously described methodologies $[9,10]$ which were modified for this study. Briefly, the roots of each tooth were removed and the crown was cut (using a diamond saw under water irrigation) from the distal, mesial, buccal, and lingual side. Hence, 96 samples were obtained from 24 teeth. To facilitate measuring of roughness parameters, circular molds of $16 \mathrm{~mm}$ in diameter and $3 \mathrm{~mm}$ deep were filled by self-cured resin. Each sample was embedded in resin, with labial (oral) surfaces uppermost, and was cleaned with nonfluoridated pumice, rinsed with water and dried with oilfree compressed air.

The samples were randomly assigned to 5 experimental groups - (1) Coca-Cola, (2) orange juice, (3) Cedevita, (4) Guarana, (5) strawberry yoghurt - and a control group. Each experimental group consisted of 18 samples, 6 for each time of exposure $(15,30$ and $60 \mathrm{~min}) ; 6$ control samples were stored in filtered saliva.

The samples were exposed to $50 \mathrm{ml}$ of soft drinks at room temperature for 15, 30 and $60 \mathrm{~min}$, with occasional shaking. After rinsing with distilled water, the samples were left in filtered saliva until the next immersion. Daily cycles were performed in 3 immersions. Since the experiment lasted for 10 days, each sample was immersed 30 times in total.

Human saliva was collected from healthy volunteers in the morning, $2 \mathrm{~h}$ after fasting. Volunteers rinsed their mouths twice with distilled water before saliva collection [11]. Filtrates were obtained with Whatman filter papers grade 1:11 $\mu \mathrm{m}$ (Sigma-Aldrich, USA).

Surface roughness of the enamel samples was measured using a profilometer (Mitutoyo Surftest SJ-301) [12]. The points of roughness measurement were randomly marked on the sample surface. Measurements were carried out perpendicularly to the samples. For each sample, 3 measurements were made, and the mean value was calculated $[10,13]$. The roughness parameters assessed were the following: $\mathrm{R}_{\mathrm{a}}$ (defined as the average distance from the profile to the mean line over the length of assessment), $R_{q}$ (defined as the square root of the arithmetic mean of the squares of profile deviations from the mean line, $\mathrm{R}_{\mathrm{z}}$ (defined as the peak-tovalley values of five equal lengths within the profile, and $R_{y}$ (defined as the distance between peak and valley points of the profile, which can be used as an indicator of the maximum defect height within the assessed profile). All of the parameters were characterized by the International Standards Organization [14].

Erosive Effect of Soft Drinks on Enamel
Table 2. Initial $\mathrm{pH}$ and $\mathrm{TA}$ of the different soft drinks

\begin{tabular}{llll}
\hline Soft drinks & Initial pH & TA & \\
\cline { 3 - 4 } & & pH 5.5 & pH 7.0 \\
\hline Coca-Cola & $2.67 \pm 0.06$ & $0.56 \pm 0.02$ & $1.87 \pm 0.09$ \\
Orange juice & $3.73 \pm 0.03$ & $4.24 \pm 0.01$ & $5.70 \pm 0.06$ \\
Cedevita & $3.49 \pm 0.03$ & $2.30 \pm 0.07$ & $3.40 \pm 0.08$ \\
Guarana & $2.52 \pm 0.06$ & $3.41 \pm 0.06$ & $5.11 \pm 0.01$ \\
Strawberry yoghurt & $4.21 \pm 0.17$ & $2.02 \pm 0.03$ & $3.52 \pm 0.03$ \\
\hline
\end{tabular}

TA: amount of base (milliliters of $1.0727 \mathrm{M} \mathrm{NaOH}$ ) needed to raise the $\mathrm{pH}$ to 5.5 and 7.0.

The measuring force of the scanning arm on the surfaces was $4 \mathrm{mN}$ (0.4 gram-force) $[10,12,13]$ which, according to the Mitutoyo Surftest SJ-301 user manual, did not cause any significant damage on the surface, and the pin was calibrated before the tests [15].

The study was conducted under the following conditions: the temperature was $25^{\circ} \mathrm{C}$, the movement speed of the diamond stylus was $0.25 \mathrm{~mm} / \mathrm{s}$, the length of the measuring line was $0.5 \mathrm{~mm}$, and the cutoff was $2.5 \mathrm{~mm}$. In order to exclude possible errors, measurement of surface roughness was done by only one examiner. Statistical analysis was carried out using one-way ANOVA Student-Newman-Keuls post hoc test.

\section{Results}

\section{Results of pH Measurement}

All of the analyzed soft drinks had initial $\mathrm{pH}$ values below critical ( $\mathrm{pH}$ 5.5). Guarana and Coca-Cola had the lowest average $\mathrm{pH}$ value $(2.52 \pm 0.06$ and $2.67 \pm 0.06$, respectively), whereas strawberry yoghurt and orange juice had the highest $(4.21 \pm 0.17$ and $3.73 \pm 0.03$, respectively). The $\mathrm{pH}$ value of Cedevita was $3.49 \pm 0.03$. There was no statistically significant difference in the initial $\mathrm{pH}$ value of Guarana and Coca-Cola $(\mathrm{p}>0.05)$.

\section{Results of TA}

Titrations of up to $\mathrm{pH} 5.5$ and 7.0 were repeated 3 times for each soft drink sample. Since there was no statistically significant difference in TA between different samples of one drink type, it was possible to compare mean values of these parameters in all of the soft drink groups (table 2). Coca-Cola required only $1.87 \mathrm{ml}$ of $\mathrm{NaOH}$ to reach a $\mathrm{pH}$ value of 7.0, whilst orange juice gave the greatest TA, requiring $5.70 \mathrm{ml}$ of $\mathrm{NaOH}$ to reach the equivalent $\mathrm{pH}$ value. Table 2 represents the initial $\mathrm{pH}$ and TA, i.e. amount of base needed to raise the $\mathrm{pH}$ to 5.5 and 7.0 of the different soft drinks. 
Table 3. The values of the enamel surface roughness parameters in relation to the type of soft drink

\begin{tabular}{|c|c|c|c|c|c|c|}
\hline Exposure, min & Roughness parameters & Coca-Cola & Orange juice & Cedevita & Guarana & Strawberry yoghurt \\
\hline 15 & $\begin{array}{l}\mathrm{R}_{\mathrm{a}} \\
\mathrm{R}_{\mathrm{q}} \\
\mathrm{R}_{\mathrm{z}} \\
\mathrm{R}_{\mathrm{y}}\end{array}$ & $\begin{array}{r}1.49 \pm 0.08 \\
2.60 \pm 0.08 \\
10.55 \pm 1.57 \\
19.11 \pm 0.95\end{array}$ & $\begin{array}{r}1.27 \pm 0.01^{\mathrm{a}} \\
1.67 \pm 0.07^{\mathrm{a}} \\
6.16 \pm 0.43^{\mathrm{a}} \\
10.67 \pm 0.82^{\mathrm{a}}\end{array}$ & $\begin{array}{l}1.09 \pm 0.03^{\mathrm{a}, \mathrm{b}} \\
1.38 \pm 0.06^{\mathrm{a}, \mathrm{b}} \\
4.49 \pm 0.40^{\mathrm{a}, \mathrm{b}} \\
6.92 \pm 0.58^{\mathrm{a}, \mathrm{b}}\end{array}$ & $\begin{array}{l}1.07 \pm 0.02^{\mathrm{a}, \mathrm{b}} \\
1.22 \pm 0.14^{\mathrm{a}-\mathrm{c}} \\
4.46 \pm 0.46^{\mathrm{a}, \mathrm{b}} \\
6.39 \pm 0.93^{\mathrm{a}, \mathrm{b}}\end{array}$ & $\begin{array}{l}0.67 \pm 0.02^{\mathrm{a}-\mathrm{d}} \\
0.80 \pm 0.03^{\mathrm{a}-\mathrm{d}} \\
1.67 \pm 0.07^{\mathrm{a}-\mathrm{d}} \\
4.69 \pm 0.46^{\mathrm{a}-\mathrm{d}}\end{array}$ \\
\hline 30 & $\begin{array}{l}\mathrm{R}_{\mathrm{a}} \\
\mathrm{R}_{\mathrm{q}} \\
\mathrm{R}_{\mathrm{z}} \\
\mathrm{R}_{\mathrm{y}}\end{array}$ & $\begin{array}{l}1.63 \pm 0.05 \\
2.11 \pm 0.02 \\
5.62 \pm 0.01 \\
9.27 \pm 0.22 \\
\end{array}$ & $\begin{array}{l}1.63 \pm 0.02 \\
2.10 \pm 0.03 \\
5.37 \pm 0.15^{\mathrm{a}} \\
9.09 \pm 0.22 \\
\end{array}$ & $\begin{array}{l}1.14 \pm 0.03^{\mathrm{a}, \mathrm{b}} \\
1.43 \pm 0.07^{\mathrm{a}, \mathrm{b}} \\
4.69 \pm 0.46^{\mathrm{a}, \mathrm{b}} \\
6.48 \pm 0.66^{\mathrm{a}, \mathrm{b}}\end{array}$ & $\begin{array}{l}1.11 \pm 0.02^{\mathrm{a}, \mathrm{b}} \\
1.42 \pm 0.06^{\mathrm{a}, \mathrm{b}} \\
4.59 \pm 0.51^{\mathrm{a}, \mathrm{b}} \\
6.12 \pm 0.58^{\mathrm{a}, \mathrm{b}}\end{array}$ & $\begin{array}{l}0.67 \pm 0.02^{\mathrm{a}-\mathrm{d}} \\
0.79 \pm 0.05^{\mathrm{a}-\mathrm{d}} \\
1.68 \pm 0.08^{\mathrm{a}-\mathrm{d}} \\
4.73 \pm 0.43^{\mathrm{a}-\mathrm{d}}\end{array}$ \\
\hline 60 & $\begin{array}{l}\mathrm{R}_{\mathrm{a}} \\
\mathrm{R}_{\mathrm{q}} \\
\mathrm{R}_{\mathrm{z}} \\
\mathrm{R}_{\mathrm{y}}\end{array}$ & $\begin{array}{r}1.82 \pm 0.01 \\
2.57 \pm 0.02 \\
7.80 \pm 0.29 \\
13.96 \pm 0.57\end{array}$ & $\begin{array}{r}1.78 \pm 0.07 \\
2.49 \pm 0.18 \\
7.68 \pm 0.30 \\
12.86 \pm 1.66\end{array}$ & $\begin{array}{l}1.20 \pm 0.04^{\mathrm{a}, \mathrm{b}} \\
1.48 \pm 0.07^{\mathrm{a}, \mathrm{b}} \\
4.73 \pm 0.43^{\mathrm{a}, \mathrm{b}} \\
7.05 \pm 1.28^{\mathrm{a}, \mathrm{b}}\end{array}$ & $\begin{array}{l}1,20 \pm 0.04^{\mathrm{a}, \mathrm{b}} \\
1.43 \pm 0.11^{\mathrm{a}, \mathrm{b}} \\
4.88 \pm 0.26^{\mathrm{a}, \mathrm{b}} \\
6.22 \pm 0.63^{\mathrm{a}, \mathrm{b}}\end{array}$ & $\begin{array}{l}0.68 \pm 0.05^{\mathrm{a}-\mathrm{d}} \\
0.85 \pm 0.08^{\mathrm{a}-\mathrm{d}} \\
1.74 \pm 0.13^{\mathrm{a}-\mathrm{d}} \\
4.81 \pm 1.00^{\mathrm{a}-\mathrm{d}}\end{array}$ \\
\hline
\end{tabular}

${ }^{\mathrm{a}} \mathrm{p}<0.05$ vs. Coca-Cola; ${ }^{\mathrm{b}} \mathrm{p}<0.05$ vs. orange juice; ${ }^{\mathrm{c}} \mathrm{p}<0.05$ vs. Cedevita; ${ }^{\mathrm{d}} \mathrm{p}<0.05$ vs. Guarana.

Table 4. The values of the enamel surface roughness parameters in relation to time of exposure to soft drinks

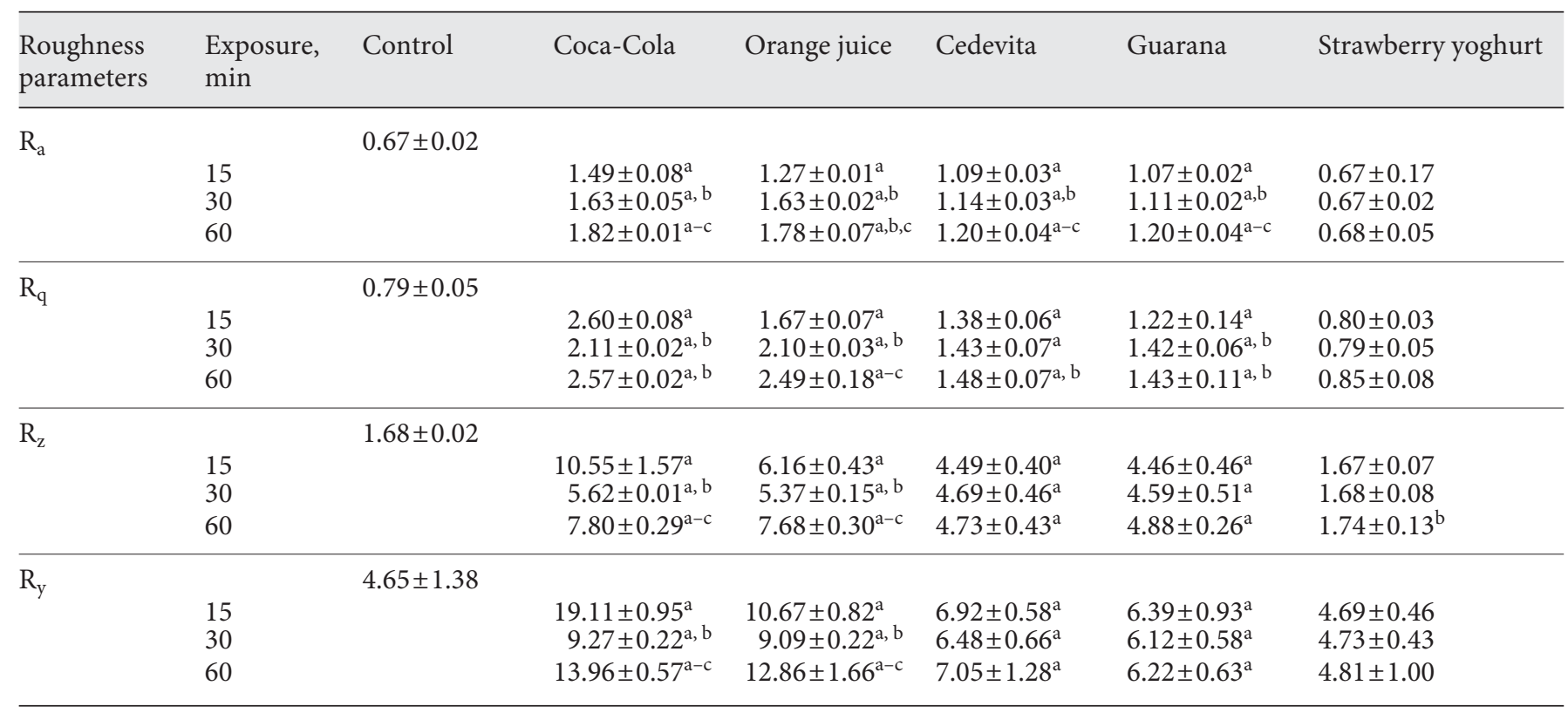

${ }^{\mathrm{a}} \mathrm{p}<0.05$ vs. control; ${ }^{\mathrm{b}} \mathrm{p}<0.05$ vs. $15 \mathrm{~min} ;{ }^{\mathrm{c}} \mathrm{p}<0.05$ vs. $30 \mathrm{~min}$.

Results of Enamel Roughness Measurement

Profilometric parameters showed that surface roughness of the enamel increased with time due to exposure to soft drinks (tables 3 and 4).

The highest value of enamel surface roughness parameters was observed in the samples immersed in Coca-Cola for 15 min compared to other soft drinks with the same time interval. There was no significant difference in pa- rameter values between samples immersed in Coca-Cola and orange juice for 30 and $60 \mathrm{~min}$. Similar parameters were established for Cedevita and Guarana, regardless of exposure time. It was determined that enamel specimens immersed in strawberry yoghurt did not show a statistically significant difference in parameters compared to the control samples (except for $\mathrm{R}_{\mathrm{z}}$ parameter for $60 \mathrm{~min}$ compared to 15 -min time intervals). 


\section{Discussion}

Since this research showed that all of the 5 tested soft drinks had a $\mathrm{pH}$ value below critical (pH 5.5), it was possible to expect the initial demineralization of enamel. Carbonated drinks, Guarana and Coca-Cola had the lowest $\mathrm{pH}$ values (2.52 and 2.67, respectively). Guarana was expected to have a stronger erosive effect than Coca-Cola because it had a lower initial $\mathrm{pH}$ and higher TA $(3.41 \mathrm{ml}$ to reach $\mathrm{pH} 5.5$, and $5.11 \mathrm{ml}$ to reach $\mathrm{pH}$ 7.0). There are few literature data on the erosive potential of Guarana and its effect on dental tissues. De Carvalho Sales-Peres et al. [16] discussed the effect of additional substances which may modify the erosive potential of this energy drink. Their research showed that Guarana had a $\mathrm{pH}$ of 3.2 , which is in contrast to the results in the present study. Apart from guarana fruit extract, Guarana contains sodium benzoate, carbon monoxide, flavonoids, tannins, and vitamins which can have a protective effect in dental erosion, although there are no studies to confirm this assumption.

The presence of various acids can explain the differences in the erosive potential of Coca-Cola and Guarana. According to information from the manufacturers, CocaCola contains phosphoric acid, whereas Guarana contains citric acid. Compared to citric acid, phosphoric acid is stronger [17]. However, literature data regarding the erosive potential of soft drinks containing citric or phosphoric acid are contradictory $[5,16,18]$. The effect of phosphoric acid results in a superficial etched zone which might be permanently lost from the tooth surface [19]. On the other hand, citric acid may act as a chelator capable of binding the calcium from enamel or dentine, thus increasing the degree of undersaturation and favoring demineralization [20,21].

The results of this study show that Coca-Cola had the highest erosive potential in the shortest time interval exposure $(15 \mathrm{~min})$, although it had the lowest TA. These results are in accordance with literature data which show that cola-based drinks have a higher erosive potential than orange juices (which contain citric acid) immediately after exposure [18]. Profilometric parameters in this study have demonstrated that pure orange juice causes greater enamel erosion during longer exposures. A statistically significant lower degree of roughness compared to Coca-Cola in shorter exposure can be explained by higher initial $\mathrm{pH}$ in orange juice compared to Coca-Cola (3.73 vs. 2.67). As well as citric acid, orange juice contains many different weak organic acids such as ascorbic, malic, tartaric, and oxalic acid, which may be regarded as buffer components [7]. Besides, orange juice had the highest TA compared to other tested drinks.

Although they have different initial pH (3.49 and 2.52), Cedevita and Guarana showed similar erosive potential, probably because of TA values, which do not differ greatly. Both drinks contain citric acid and vitamin mix (Cedevita also contains sodium hydrogen carbonate betaine, $\beta$-carotene).

In the present study the $\mathrm{pH}$ and TA of strawberry yoghurt were not correlated with its erosive potential. Roughness parameters showed a statistically significant difference compared to the other tested soft drinks, and they do not deviate significantly from the control samples. Although its initial $\mathrm{pH}$ was below critical and the TA lower than in orange juice and significantly higher than in Coca-Cola, yoghurt did not erode the enamel. This can be explained by a high concentration of calcium and phosphates which probably minimize the demineralization process. Calcium and phosphate levels cause saturation for apatite, and this prevents the exit of these ions from the enamel [22]. Recently, it has been concluded that fruit yoghurts caused material loss of enamel in vitro to some degree, but without detectable erosive effects [22]. The role of fruit in determining the TA of fruit yoghurts is significant. It has been determined that strawberry yoghurt is slightly unsaturated with respect to hydroxyapatite and saturated with respect to fluorapatite compared to other fruit yoghurts, which are saturated with respect to both apatites [22].

It can be assumed that the initial erosive potential of soft drinks depends solely on $\mathrm{pH}$, whereas buffer properties (buffering capacity or TA) become important later, when there is a longer contact between the enamel and the drink $[2,18]$. The significance of the soft drink buffer properties in the etiology of dental erosion has already been demonstrated by several authors $[1,2,4,7]$.

Stylus profilometry is widely used to measure enamel and dentin surface loss [8-10,23-26]. Although there are literature data that show some disadvantages of stylus profilometry (inability to detect valleys which are narrower than the stylus tip, the risk of the diamond tip causing damage to the specimens), this technique has a high degree of precision [27]. Moreover, the current national standards on measuring surface texture are defined using stylus profilometry $[14,27]$.

As for sample preparation, the methodology used in this research differs from methodologies in other studies $[3,8,10,13]$. Enamel samples were not ground flat or mechanically treated in any way before immersion into acidic solutions. The surface of the sample was only cleaned 
with nonfluoridated pumice with no mechanical damage before placement into erosive solutions [26]. Grinding or flattening removes a certain amount of enamel which can become more sensitive to acidic solutions, and irregularities which develop on the sample surface do not have to be a consequence only of erosion but also of grinding. According to Elton et al. [28], this removes significant amounts of enamel, possibly the complete aprismatic layer. This leads to more rapid lesion progression, without replicating the in vivo situation.

The most common form of reporting roughness is the surface roughness average $\left(R_{a}\right.$, arithmetic average) [27]. However, this parameter provides no information on the characteristics of surface irregularities, whereby both maximal and minimal irregularities may show the same $R_{a}$ values [13,27]. To determine profile shape, additional roughness variables such as $R_{\mathrm{q}}, \mathrm{R}_{\mathrm{z}}$ and $\mathrm{R}_{\mathrm{y}}$ may be recommended $[12,26]$.

In the present study, all of the enamel surface roughness parameters showed the highest values for Coca-Cola and orange juice in comparison to other drinks in all of the exposure times. The $\mathrm{R}_{\mathrm{a}}$ parameter showed a statistically significant increase in surface roughness for all of the tested drinks (except yoghurt) with increasing time of exposure. This result was also observed in similar studies $[3,9]$, regardless of the different sample preparation protocols. According to other roughness parameters, the positive relationship between the erosive potential and exposure time was not always observed. For instance, the parameters $R_{q}, R_{z}$ and $R_{y}$ showed a significant decrease for 30 and $60 \mathrm{~min}$ of exposure compared to a 15-min exposure to Coca-Cola. This can be explained by the assumption that Coca-Cola at short exposure times erodes enamel 'more evenly' compared to long exposures.

Roughness parameters $\mathrm{R}_{\mathrm{z}}$ and $\mathrm{R}_{\mathrm{y}}$ for Guarana and Cedevita showed higher values with exposure time, but this was not statistically significant. The profilometric testing showed that Guarana had low erosive potential, which is consistent with other reports [16]. So far, there have been no literature data about the erosive potential of Cedevita concerning dental erosion.

As for the strawberry yoghurt, only one parameter $\left(R_{z}\right)$ had statistically significant values during a 60 -min exposure. Since there was no significant difference between other roughness parameters compared to control samples, the high $\mathrm{R}_{\mathrm{z}}$ value can be explained by morphological characteristics of the samples rather than by the results of the erosive effect of the yoghurt.

Overall, the results of this study did not much differ from the results obtained from other studies with similar goals, regardless of the method of sample preparation. It seems that the noncontact optical profilometry method is accepted by most authors $[10,13,23,25]$, whereas the sample preparation for this methodology is still not unique [28].

Also, the method used in the present study may represent a limitation because it only registers irregularities but not the quantity of lost enamel $[13,25]$. This may explain why, for instance, some enamel roughness parameters show lower values for a 30-min exposure compared to a 15-min exposure to soft drinks. Many authors have suggested the complexity of the erosive process and the fact that in vitro studies cannot totally reproduce the clinical conditions as possible reasons. In vitro studies should only be interpreted as a prediction of the relative erosive potential of a soft drink $[2,4,21]$. Erosion is a multifactorial condition, and its occurrence and development depend on many risk and protective factors as well as on their interplay $[4,17]$. Therefore, it requires more than one type of analysis $[3,4]$.

Further research studies are necessary in order to improve the understanding of the precise mechanism which participates in erosion progression. Although this study cannot completely show the complex oral environment, it confirms the erosive potential of some acidic soft drinks in relation to the time of exposure.

\section{Conclusion}

Despite the limitations of in vitro studies, all of the tested soft drinks (except strawberry yoghurt) were found to be erosive. Tooth erosion had a significant relationship with $\mathrm{pH}$ and TA. Erosion of the enamel surfaces exposed to Coca-Cola, orange juice, Cedevita, and Guarana was proportional to the exposure time.

\section{Acknowledgment}

This work received support from the Serbian Ministry of Science and technology, Republic of Serbia (TR 31060).

\section{Disclosure Statement}

The authors have no conflicts of interest to declare. 


\section{References}

$>1$ Cairns AM, Watson M, Creanor SL, et al: The $\mathrm{pH}$ and titratable acidity of a range of diluting drinks and their potential effect on dental erosion. J Dent 2002;30:313-317.

$>2$ Benjakul P, Chuenarrom C: Association of dental enamel loss with the $\mathrm{pH}$ and titratable acidity of beverages. J Dent Sci 2011;6:129133.

>3 Goncalves GK, Guglielmi Cde A, Correa FN, et al: Erosive potential of different types of grape juices. Braz Oral Res 2012;26:457-463.

$\checkmark 4$ Lussi A, Megert B, Shellis RP, et al: Analysis of the erosive effect of different dietary substances and medications.Br J Nutr 2012;107: 252-262.

$>5$ Torres CP, Chinelatti MA, Gomes-Silva JM, et al: Surface and subsurface erosion of primary enamel by acid beverages over time. Braz Dent J 2010;21:337-345.

6 Jager DH, Vieira AM, Ruben JL, et al: Estimated erosive potential depends on exposure time. J Dent 2012;40:1103-1108.

7 Edwards M, Creanor SL, Foye RH, et al: Buffering capacities of soft drinks: the potential influence on dental erosion. J Oral Rehabil 1999;26:923-927.

$>8$ Heurich E, Beyer M, Jandt KD, et al: Quantification of dental erosion - a comparison of stylus profilometry and confocal laser scanning microscopy (CLSM). Dent Mater 2010; 26:326-336

$>9$ Fujii M, Kitasako Y, Sadr A, et al: Roughness and $\mathrm{pH}$ changes of enamel surface induced by soft drinks in vitro - applications of stylus profilometry, focus variation 3D scanning microscopy and micro $\mathrm{pH}$ sensor. Dent Mater J 2011;30:404-410.
10 Chuenarrom C, Benjakul P: Comparison between a profilometer and a measuring microscope for measurement of enamel erosion. J Oral Sci 2008;50:475-479.

11 Jiang J, Park NJ, Hu S, et al: A universal preanalytic solution for concurrent stabilization of salivary proteins, RNA and DNA at ambient temperature. Arch Oral Biol 2009;54:268273.

12 Korkut DS, Korkut S, Bekar I, et al: The effects of heat treatment on the physical properties and surface roughness of Turkish Hazel (Corylus colurna L.) wood. Int J Mol Sci 2008;9: 1772-1783.

13 Ren YF, Zhao Q, Malmstrom H, et al: Assessing fluoride treatment applications of focus variation 3D scanning microscopy and stylus profilometry. J Dent 2009;37:167-176.

14 International Standards Organization: Geometrical Product Specifications (GPS). Surface Texture: Profile Method; Measurement Standards. Standard I. ISO, 2001.

15 Anonymous: Mitutoyo Surface Roughness Tester - Mitutoyo Surftest SJ-301. Kanagawa, Mitutoyo Corporation, 2002.

-16 de Carvalho Sales-Peres SH, Magalhaes AC, de Andrade Moreira Machado MA, et al: Evaluation of the erosive potential of soft drinks. Eur J Dent 2007;1:10-13.

17 Lussi A, Jaeggi T: Erosion - diagnosis and risk factors. Clin Oral Investig 2008;12(suppl 1):S5-S13.

-18 Jensdottir T, Holbrook P, Nauntofte B, et al: Immediate erosive potential of cola drinks and orange juices. J Dent Res 2006;85:226230 .
19 Carstensen W: The effects of different phosphoric acid concentrations on surface enamel. Angle Orthod 1992;62:51-58.

20 West NX, Hughes JA, Addy M: The effect of $\mathrm{pH}$ on the erosion of dentine and enamel by dietary acids in vitro. J Oral Rehabil 2001;28: 860-864.

-21 Wang YL, Chang CC, Chi CW, et al: Erosive potential of soft drinks on human enamel: an in vitro study. J Formos Med Assoc 2014;113. 850-856.

22 Caglar E, Lussi A, Kargul B, et al: Fruit yogurt: any erosive potential regarding teeth? Quintessence Int 2006;37:647-651.

-23 Passos VF, Melo MA, Vasconcellos AA, et al: Comparison of methods for quantifying dental wear caused by erosion and abrasion. Microsc Res Tech 2013;76:178-183.

24 Cerci BB, Roman LS, Guariza-Filho O, et al: Dental enamel roughness with different acid etching times: atomic force microscopy study. Eur J Gen Dent 2012;1:187-191.

25 Paepegaey AM, Barker ML, Barlett DW, et al: Measuring enamel erosion: a comparative study of contact profilometry, non-contact profilometry and confocal laser scanning microscopy. Dent Mater 2013;29:1265-1272.

26 Karan S, Kircelli BH, Tasdelan B: Enamel surface roughness after debonding. Angle Orthod 2010;80:1081-1088.

27 Field J, Waterhouse P, German M: Quantifying and qualifying surface changes on dental hard tissue in vitro. J Dent 2010;38:182-190.

$\checkmark 28$ Elton V, Cooper L, Higham SM, et al: Validation of enamel erosion in vitro. J Dent 2009; $37: 336-341$. 